\title{
Ambidextrous Oriented Organizational Attributes, Knowledge Acquisition Modes and Enterprises' Radical Innovation
}

\author{
Huimin Li, Qingpu Zhang* \\ School of Economics and Management, Harbin Institute of Technology, Harbin 250001, China. \\ *zzqp2000@126.com
}

Keywords: Organizational attributes; radical innovation; control-oriented; knowledge explorations.

\begin{abstract}
In this paper, the function mechanism of the ambidextrous oriented (control-oriented and flexibility-oriented) organizational attributes-centralization, formalization, risk taking and organizational redundancy on the enterprises' radical innovation was discussed. The two knowledge acquisition modes, namely knowledge exploration and knowledge exploitation, were introduced to be as the mediating variables to construct the conceptual model of "organizational attributes knowledge acquisition - radical innovation", and then the structural equation model was applied to carry out the empirical researches to the enterprises with active radical innovation in Yangtze River delta region. The results show that: (1) the control-oriented organizational attributes have a negative effect on the knowledge exploration and the radical innovation; (2)the flexibility-oriented organizational attributes have a positive effect on the knowledge exploration and the radical innovation; (3) the flexibility-oriented organizational attributes have no significant effect on the knowledge exploitation; (4) the knowledge exploration played a mediating effect on the organizational attributes and the radical innovation; (5) the knowledge exploitation has no significant mediating effect on the organizational attributes and radical innovation.
\end{abstract}

\section{Introduction}

With the importance of disruptive innovation for enterprises, industries and even countries, the academic circles pay more and more attention to radical innovation research. Through the creation of a new technology track and economic paradigm, breakthrough innovation can have great subversion to the existing technology and products. Through the breakthrough innovation, the enterprises can shake the competitive base of the large enterprises and end the absolute monopoly [1], thus opening a new market. Although scholars have made a more in-depth study on the relationship between organizational properties and breakthrough innovation based on various angles, the influence and influence degree of these factors on breakthrough innovation are discussed, but the research results are fragmentary, and the fundamental reasons for the effect of these attributes to breakthrough innovation are not systematically summarized. Therefore, on the basis of the existing research, this paper, based on the structure, strategy, resources and entrepreneurial spirit of the enterprise, divides the organizational attributes into control oriented and flexible guidance (dual orientation) based on the "plan" and "randomness" of the organizational attributes, and selects the centralization, normalization and risk taking[2]. The four most typical organizational attributes of redundant resources are to explore the mechanism of their effects on radical innovation.

\section{Theoretical Basis and Research Hypothesis}

\subsection{Dual Oriented Organizational Attributes and Breakthrough Innovation.}

Enterprise breakthrough innovation is closely related to organizational attributes. Specific organizational attributes can help companies allocate resources and new technologies rationally to achieve radical innovation. Radical innovation is not only related to the attributes of individual organizations, but also more closely related to the effect of the combination of various attributes. [3] This paper tries to explore from the perspective of organizational attributes, and divides the organizational attributes into dual orientation, control orientation and flexible orientation, and the 
corresponding organizational attributes select the most representative attributes of four typical attributes such as centralization, normalization, risk bearing and organizational redundancy.

Centralization reflects the extent to which the decision-making power of an organization is concentrated on top management. Centralization makes the communication channel narrow in the organization, restricts the communication and sharing of knowledge and information among the members of the organization, inhibits the emergence of new ideas and new ideas, and eventually hinders the formation of unconventional solutions. Normalization reflects the extent to which the organization uses formal regulations to regulate employees' roles, responsibilities, processes and performance standards. Therefore, normalization is not conducive to breakthrough innovation. The connotation of risk is to allow organizations to allocate resources to projects with uncertain return rates. From the perspective of contribution and adaptability, the organizational attributes of risk can improve the adaptability of enterprises, thereby increasing the success rate of radical innovation.

\subsection{Knowledge Acquisition Mode and Breakthrough Innovation.}

Knowledge acquisition theory points out that enterprises can gain innovative benefits by balancing the use of existing knowledge assets and exploring two kinds of knowledge acquisition models of new knowledge. Pole and other scholars have pointed out that breakthrough innovation should have a new knowledge base, because breakthroughs and existing technologies are based on completely different scientific principles [4]. The novelty view of the knowledge base holds that the breakthrough innovation has a greater difference in the source and structure of knowledge compared with the progressive innovation. The former is more demanding for the novelty and uniqueness of knowledge, because the relevance of the novelty knowledge to the old technology track is weak [5], and the exploration of this new knowledge is more conducive to the breakthrough innovation.

\section{Empirical Analysis}

In this paper, the data collection is collected by questionnaire, and the data are collected mainly in the Yangtze River Delta, which is more active in the breakthrough innovation activities [6]. Through e-mail and on-site questionnaires, the senior managers who have served more than one year are asked to fill out the questionnaire: a total of 450 questionnaires are issued, and 258 valid questionnaires are finally recovered.

Table 1. Outcomes of Model Fitting

\begin{tabular}{ccccccccccc}
\hline & $\chi 2 / \mathrm{df}$ & RMSER & RMR & GFI & AGFI & NFI & RFI & IFI & TLI & CFI \\
\hline $\begin{array}{c}\text { research } \\
\text { model }\end{array}$ & 1.328 & 0.036 & 0.067 & 0.913 & 0.888 & 0.913 & 0.897 & 0.977 & 0.973 & 0.977 \\
conclusion & fulfil & fulfil & fulfil & fulfil & fulfil & fulfil & fulfil & fulfil & fulfil & fulfil \\
\hline
\end{tabular}

In this study, AMOS 21.0 is used to construct the structural equation model, and the maximum likelihood estimation method is adopted. According to the fitting results of the theoretical model of Table 1, it is found that the / $\mathrm{df}$ is less than 4, RMSEA is less than 0.08, RMR is less than 0.08, GFI, NFI, RFI, IFI, TLI, and CFI are all greater than 0.9, indicating that the structural model of this study has a higher fitting degree.

From Table 2, we can see that the two kinds of control oriented organizational attributes of centralization and regularization have a significant negative impact on breakthrough innovation, and the two flexible organizational attributes of risk bearing and organizational redundancy have a significant positive impact on breakthrough innovation[7]. Knowledge exploration has a significant positive impact on breakthrough innovation; knowledge utilization is a breakthrough. The impact of sexual innovation is not significant, centralization and normalization have significant negative impact on knowledge exploration; risk bearing and organizational redundancy have significant positive effects on knowledge exploration, and centralization and normalization have significant positive effects on knowledge utilization. 
It is known from Table 3 that there is a significant correlation between independent variables, intermediary variables and dependent variables, and the AVE square roots are larger than the correlation coefficients between variables. This indicates that the common variation among variables is not very high, and the latent variables of this study have a better difference validity [8].

Table 2. Model analysis results

\begin{tabular}{|c|c|c|c|c|c|c|c|}
\hline \multicolumn{2}{|c|}{ Latent variable } & $\begin{array}{l}\text { Observation } \\
\text { variable }\end{array}$ & \multicolumn{2}{|c|}{$\begin{array}{l}\text { Factor load } \\
\text { coefficient }\end{array}$} & $\begin{array}{l}\text { Cronbach's } \\
\alpha \text { coefficient }\end{array}$ & $\begin{array}{l}\text { composite } \\
\text { reliability }\end{array}$ & AVE \\
\hline \multirow{3}{*}{\multicolumn{2}{|c|}{ Centralization }} & CENT1 & & & \multirow{3}{*}{0.879} & \multirow{3}{*}{0.881} & \multirow{3}{*}{0.712} \\
\hline & & CENT2 & & & & & \\
\hline & & CENT3 & & & & & \\
\hline \multirow{4}{*}{\multicolumn{2}{|c|}{ Normalization }} & FORM1 & & & \multirow{4}{*}{0.891} & \multirow{4}{*}{0.892} & \multirow{4}{*}{0.674} \\
\hline & & FORM2 & & & & & \\
\hline & & FORM3 & & & & & \\
\hline & & FORM4 & & & & & \\
\hline \multirow{3}{*}{\multicolumn{2}{|c|}{ Risk bearing }} & RT1 & & & \multirow{3}{*}{0.798} & \multirow{3}{*}{0.802} & \multirow{3}{*}{0.575} \\
\hline & & RT2 & & & & & \\
\hline & & RT3 & & & & & \\
\hline \multirow{3}{*}{\multicolumn{2}{|c|}{$\begin{array}{l}\text { Organizational } \\
\text { redundancy }\end{array}$}} & OR1 & & & \multirow{3}{*}{0.896} & \multirow{3}{*}{0.895} & \multirow{3}{*}{0.74} \\
\hline & & OR2 & & & & & \\
\hline & & OR3 & & & & & \\
\hline \multirow{3}{*}{\multicolumn{2}{|c|}{$\begin{array}{l}\text { Knowledge } \\
\text { exploration }\end{array}$}} & EXPR1 & & & \multirow{3}{*}{0.813} & \multirow{3}{*}{0.804} & \multirow{3}{*}{0.578} \\
\hline & & EXPR2 & & & & & \\
\hline & & EXPR3 & & & & & \\
\hline \multirow{3}{*}{\multicolumn{2}{|c|}{$\begin{array}{l}\text { Knowledge } \\
\text { utilization }\end{array}$}} & EXPI1 & & & \multirow{3}{*}{0.902} & \multirow{3}{*}{0.901} & \multirow{3}{*}{0.752} \\
\hline & & EXPI2 & & & & & \\
\hline & & EXPI3 & & & & & \\
\hline \multirow{4}{*}{\multicolumn{2}{|c|}{$\begin{array}{l}\text { Breakthrough } \\
\text { innovation }\end{array}$}} & RI1 & & & \multirow{4}{*}{0.852} & \multirow{4}{*}{0.858} & \\
\hline & & RI2 & & & & & \\
\hline & & RI3 & & & & & 0603 \\
\hline & & RI4 & & & & & 0.603 \\
\hline & $\mathrm{Tab}$ & le 3. Correlati & n coeff & ient and AV & VE square ro & & \\
\hline & Centralization & regularization & $\begin{array}{c}\text { risk } \\
\text { taking }\end{array}$ & $\begin{array}{c}\text { organizational } \\
\text { redundancy }\end{array}$ & $\begin{array}{l}\text { knowledge } \\
\text { exploration }\end{array}$ & $\begin{array}{c}\text { Knowledge } \\
\text { utilization }\end{array}$ & $\begin{array}{l}\text { Breakthroug } \\
\mathrm{h} \text { innovation }\end{array}$ \\
\hline lization & 0.712 & & & & & & \\
\hline rization & 0.212 & 0.674 & & & & & \\
\hline aking & -0.094 & -0.115 & 0.575 & & & & \\
\hline $\begin{array}{l}\text { Zational } \\
\text { dancy }\end{array}$ & -0.096 & -0.042 & 0.229 & 0.74 & & & \\
\hline $\begin{array}{l}\text { ledge } \\
\text { ration }\end{array}$ & -0.262 & -0.318 & 0.303 & 0.311 & 0.578 & & \\
\hline $\begin{array}{l}\text { vledge } \\
\text { zation }\end{array}$ & $0.217^{*}$ & 0.192 & 0.024 & -0.119 & -0.098 & 0.752 & \\
\hline $\begin{array}{l}\text { hrough } \\
\text { vation }\end{array}$ & -0.314 & -0.327 & 0.353 & 0.366 & 0.525 & -0.008 & 0.603 \\
\hline
\end{tabular}

\section{Summary}

This paper takes four typical organizational attributes as explanatory variables and knowledge acquisition mode as an intermediary variable, constructs a conceptual model that affects breakthrough innovation, and uses structural equation model to carry out empirical analysis with the enterprise of active innovation in the range of the Yangtze River Delta, and the results are found: dual orientation Organizational attributes can promote radical innovation through rational knowledge acquisition mode, and knowledge exploration plays an important intermediary role[9]. At the same 
time, we also find that in Chinese context, the impact of risk commitment and organizational redundancy on knowledge utilization is not significant, and the intermediary effect of knowledge utilization on organizational properties and breakthrough innovation is not significant.

\section{References}

[1]. Bi Xiaoping, Chen Yangchuan. From the perspective of social psychology, the innovative behavior of grass roots employees Research. Industrial technology economy, 2014, (9): $153 \sim 160$.

[2]. Wen Koi, Wu Dongle. Abnormal incentives for heterogeneous Talents -- Beijing hi tech Enterprises Research Report on talent incentive mechanism. Management world, 2003, (10):110 114.

[3]. Lu Lin, Chang He Shan. Research on the impact of goal orientation on individual innovative behavior, research and development management, 2007, 19 (6): 44 50.

[4]. Liu Yun, Shi Jin Tao. The influence of organizational innovation climate on employees' innovative behavior Investigation - Analysis of the mediating effect based on psychological empowerment. 2010, (6): 133 144.

[5]. Wen Shingling, Zhang Lei, Hour Jibe Tai. There are moderating variables and moderating agents. Mediator variables. Act psychical Sonica, 2006, 38 (3): 448-452.

[6]. Li Jamil, research on the relationship between exploratory innovation, development innovation and enterprise performance -- An Empirical Analysis Based on the effect of redundant resource adjustment. Scientific research, 2009, 9 (27).

[7]. Li Jamil, the frontier of exploratory innovation, developmental innovation and its balance. Foreign economy and management, 2009, 3 (31).

[8]. Water evergreen, Xu Lingui. Commentary on the research of enterprise innovation culture theory. Science and science and technology management, 2005 (3): 138 - 142.

[9]. Liu Yun, Shi Jin Tao. Concept formation, measurement and influence factors of the atmosphere of innovation. Science and science and technology management, 2009 (12): 70 - 75. 